Revista de Derecho

de la Pontificia Universidad Católica de Valparaíso

XXXVI (Valparaíso, Chile, 2011, $1^{\text {er }}$ Semestre)

[pp. 473 - 494]

\title{
EXAMEN CRÍTICO DEL RECURSO DE UNIFICACIÓN DE JURISPRUDENCIA
}

["Critical Examination of the Recourse for the Unification of Jurisprudence"]

\author{
Jordi Delgado Castro* \\ Universidad Católica de Temuco, Chile
}

\begin{abstract}
RESUMEN
El recurso de unificación de jurisprudencia es un recurso extraordinario que tiende a establecer una nueva forma para la función de la Corte Suprema. El análisis de las características y los aspectos procedimentales más destacables de ese recurso llevan a concluir que se va a limitar el acceso a aquella Corte sin una verdadera búsqueda de la igualdad ante la ley. Además, la consecución de una sustancial mejora en la estadística judicial y una mayor celeridad pueden influir en las próximas reformas del proceso civil.

Palabras Clave

Recurso de unificación de jurisprudencia - Reforma laboral.
\end{abstract}

Abstract

The recourse for the unification of jurisprudence is an extraordinary recourse aimed at establishing new ways for the function of the Supreme Court. The analysis of the most outstanding characteristics and procedural aspects of this recourse lead to the conclusion that the access to said Court is going to be limited without a true search for equality before the law. Also, the achievement of an important improvement in the judicial statistics and greater swiftness may have an influence in future reforms to the civil proceedings.

\section{KEYWORDS}

Recourse for the unification of jurisprudence - Labor reform.

[RECibido el 28 de octubre de 2010 y APROBADo el 18 de abril de 2011].

* Doctor en Derecho por la Universidad de Barcelona, profesor de Derecho procesal de la Facultad de Ciencias Jurídicas de la Universidad Católica de Temuco. Dirección postal: Facultad de Ciencias Jurídicas, Universidad Católica de Temuco, calle Manuel Montt 056, Campus San Francisco, Temuco, Chile. Dirección electrónica: jdelgado@uct.cl 


\section{INTRODUCCIÓN}

Una de las novedades más singulares en la llamada reforma procesal laboral fue la incorporación de un recurso de unificación de jurisprudencia. La profunda modernización que está viviendo el Derecho procesal chileno en los últimos años ha acarreado la adopción de instituciones y principios actuales y revolucionarios como el modelo de la oralidad, la introducción del procedimiento monitorio o la unificación de jurisprudencia, entre otros.

Es destacable, además, que cada uno de los pasos que se están siguiendo en el progresivo rejuvenecimiento de las prudentes figuras decimonónicas va consolidando un modelo que parece tener una apuesta directa por la consecución del debido proceso mediante la celeridad de la respuesta judicial inmutable. De este modo, la gran apuesta que parece vislumbrarse en el nuevo modelo de justicia es la prontitud en la dicción del Derecho por parte de los órganos jurisdiccionales. A tal extremo, que definitivamente se está repensando la casación con el objetivo real de que no se convierta, en ningún caso, en una tercera instancia dilatoria.

El problema que se plantea es la abdicación de sus funciones por parte de la Corte Suprema. Si bien es cierto que, como mínimo, parece cuestionable la eficacia de una sentencia que demora años y años en obtenerse, no siempre es verdad que una respuesta rápida sea equivalente a un debido proceso con todas las garantías donde, sin duda, una de las más importantes es la protección del ordenamiento jurídico que como máximo garante ha de ejercer la Corte Suprema.

\section{ANTECEDENTES}

El recurso de unificación de jurisprudencia llegó a la legislación chilena en la Ley N 20.260 que Modifica el Libro IV del Código del Trabajo y la Ley $N^{\circ} 20.087$, que establece un nuevo procedimiento laboral.

Tal recurso surgió para dar respuesta al controvertido sistema de recursos articulados en la nueva justicia laboral. En una primera etapa, el legislador diseñó un mecanismo de impugnación en materia laboral que levantó voces críticas distintas instancias ${ }^{1}$, en tanto se programaba una apelación muy restrictiva y se desterraba totalmente la casación.

${ }^{1}$ La Asociación Nacional de Magistrados, como se recoge en el Primer Informe de la Comisión de Trabajo de la Cámara de Diputados (7 de septiembre de 2004, Boletín $\mathrm{N}^{\circ}$ 3367-13), indicó acerca del sistema de recursos: "La denominación "apelación laboral" parece desafortunada, tanto porque las causales contempladas -salvo una-aluden abiertamente a una casación o nulidad, cuanto -y he aqui lo esencial de la observación, porque un recurso de instancia como el recurso de apelación (y la revisión de los hechos que lo carac- 
La reforma procesal se comenzó a gestar en iniciativas como el "Foro para la reforma de la justicia laboral y previsional" realizado los días 6 y 7 de diciembre de $2001^{2}$ en que se congregaron representantes de distintas instancias (poder judicial, poder ejecutivo, instituciones especializadas, catedráticos de universidad) para debatir y proponer cómo debía articularse un proceso laboral moderno. En lo que a nosotros interesa, debemos destacar dos ideas: se propuso mantener una apelación de naturaleza jurídica propia, con restricción de sus causales; $y$, por otra parte, se sugería eliminar el recurso de casación en la forma -debido a su poca utilización real-manteniendo el recurso de casación en el fondo cuando el fallo en segunda instancia hubiere sido dictado con infracción de ley con el objeto de mantener la uniformidad de la jurisprudencia.

Tradicionalmente, la casación ha tenido la finalidad de proteger al ordenamiento jurídico, persiguiendo las infracciones de la ley mediante el mantenimiento de una jurisprudencia uniforme ${ }^{3}$. Debemos partir, una vez más, de la premisa de no confundir el medio con el fin ${ }^{4}$. El Foro plasmó esta idea en el documento que se generó en su encuentro al afirmar que: "El recurso de casación, en el fondo, debe mantenerse cuando la sentencia de segunda instancia haya sido dictada con infracción de ley, siempre que haya influido sustancialmente en lo dispositivo de la sentencia, en análoga forma a la actual. Su objeto es mantener la uniformidad de la jurisprudencia".

Así pues, en una primera aproximación a la reforma laboral se consideró oportuno mantener el recurso de casación, reconociendo su valor como

teriza) no se aviene con el objetivo y naturaleza del juicio oral ni con la lógica que introduce tal tipo de procedimiento en materia de apreciación probatoria, especialmente con uno de sus aspectos más relevantes: que sólo puede reconocerse al juez ante quien se produce, en un acto único e irrepetible, la facultad de establecer los hechos que se dan por probados y ponderar su mérito probatorio“. Por su parte, en forma más sutil los ministros de la Corte Suprema señores Garrido, Libedinsky y Juica dejaron constancia expresa, en el Oficio $\mathrm{N}^{\circ} 2.346$, de 4 de noviembre de 2003, enviado a la Cámara de Diputados, de que la apelación contemplaba las mismas causales que la apelación y sería, por lo tanto, deseable eliminar la casación en el fondo con el objeto de evitar sucesivas casaciones.

${ }^{2}$ Disponible en www.cejamericas.org/.../2845-bases-fundamentales-para-lareforma-de-la-justicia-laboral-y-previsional-

${ }^{3}$ Romero Seguel, Alejandro, La jurisprudencia de los tribunales como fuente del Derecho (Santiago, Editorial Jurídica de Chile, 2004), p.68; Correa Selamé, Jorge, Recursos procesales civiles (Santiago, LexisNexis, 2007), p. 80.

${ }^{4}$ Aragoneses Alonso, Pedro, Notas sobre la casación y la jurisprudencia, en Revista de Derecho Procesal, 1 (2005), p. 286: "ni su función (la del recurso de casación) es la de protección de la ley (función nomofiláctica) ni la unificación ley (función uniformadora)". 
medio conducente a corregir las eventuales infracciones de ley, alcanzando, de este modo, una uniformidad en la jurisprudencia.

Resulta, entonces, de especial importancia que destaquemos esta idea que recogía el Foro y que suscribimos plenamente. La tradicional finalidad de la casación ha sido garantizar la integridad de la ley, anulando las eventuales interpretaciones erróneas o contrarias a la misma en que pudiesen incurrir los órganos jurisdiccionales 5 .

Distinto fue el camino que se siguió hasta conseguir la introducción del recurso de unificación de jurisprudencia. La tramitación de la Ley $\mathrm{N}^{\circ} 20.087$ marcó una evolución que comienza, como adelantamos, con el diseño de una apelación muy restrictiva en sus motivos, corrigiendo infracciones de ley y dejando la puerta abierta a los recursos del Código de Procedimiento Civil que en su caso correspondieran ${ }^{6}$.

Sin embargo, fueron muchas las instancias en las que, si bien se reconocía que el modelo oral requiere de una apelación distinta a como la conocíamos en tanto sólo sería posible una similar si diseñásemos una audiencia oral en segunda instancia, se insistió en que el diseño del sistema de recursos no era adecuado a los fines de la reforma ${ }^{7}$.

No fue hasta el año 2005 que se comenzaron a ver necesidades reales de incorporar un recurso de nulidad especial para atender a las necesidades del proceso laboral. El texto que presentaron los diputados Bustos, Burgos y Ceroni ${ }^{8}$ y que fue aprobado por unanimidad propuso ocho artículos en

${ }^{5}$ Serra Domínguez, Manuel, El recurso de casación en la LEC 1/2000, en Revista Jurídica de Catalunya, 4 (2001), p. 1.137; BonEt NAVARro, José, El recurso de casación civil (Cizur Menor, Aranzadi, 2010).

${ }^{6}$ El Primer Proyecto de Ley, que se vio en la Cámara de Diputados el 22 de septiembre de 2003, incluía en su artículo 490 una remisión general a los recursos que se deducen en sede de juicio ordinario civil y, por otra parte, prescribía una original apelación laboral que, en esencia, se asemejaba mucho a lo que entendemos por recurso de casación en el fondo.

${ }^{7}$ La Cámara Chilena de la Construcción señaló que el Proyecto hacía "desaparecer en la práctica” el recurso de apelación (Biblioteca Nacional del Congreso, Historia de la Ley $N^{\circ} 20.008$, pág. 169). Lamentablemente, en toda la tramitación del proyecto se instaló casi como dogma que era incompatible la doble instancia con la oralidad cuestión que ya fuera criticada hace más de setenta años por parte de la mejor doctrina: Alcalá-Zamora y Castillo, Niceto, Notas para la reforma de la Ley de Enjuiciamiento civil (Madrid, Estudios de Derecho Procesal, 1934), p. 171 ss.

${ }^{8}$ En especial, nos interesa lo previsto por los dos primeros artículos propuestos: Artículo 501 A: "La sentencia definitiva dictada con infracción de garantias constitucionales, o con infracción de ley que hubiere influido sustancialmente en lo dispositivo del fallo, será recurrible de nulidad ante la Corte de Apelaciones correspondiente. Sin perjuicio de ello, si respecto de la materia de Derecho objeto del recurso existieran distintas interpretaciones sostenidas en diversos fallos emanados de los tribunales superiores de justicia, 
que se introdujo una "pequeña casación" de la que conocería la Corte de Apelaciones, salvo que hubiere contradicción entre diversos fallos de los tribunales superiores de justicia, supuesto en el que debería intervenir la Corte Suprema para otorgar la autoridad de uniformar criterios.

De este modo, comienza tímidamente a conformarse la idea de que entregar un recurso al modo de la casación a las Cortes de Apelación implica un riesgo de dispersión de criterios jurisprudenciales que, necesariamente, deben ser corregidos por la Corte Suprema como garante de la uniformidad del ordenamiento jurídico. Esta conclusión va a ir arraigando en nuestro legislador que continuará desarrollando este modo de ver los recursos hasta nuestros más recientes días en que la Reforma Procesal Civil confirma el nuevo rol de la Corte Suprema ${ }^{10}$.

Sin embargo, el mismo año 2005 la Comisión que revisó el texto en el Senado durante los meses de septiembre y octubre ${ }^{11}$ eliminó la referencia a la Corte Suprema. Se conserva, por lo tanto, una especie de casación en el recurso de apelación laboral que, eventualmente, podrá acceder al recurso de casación en el fondo en el orden civil, debido a la remisión general a las normas de procedimiento civil.

conocerá del recurso la Corte Suprema./ En contra de la sentencia definitiva no procederán más recursos". Artículo 501 B: "Sin perjuicio de lo dispuesto en el artículo anterior, también procederá el recurso de nulidad cuando:/ a) La sentencia haya sido pronunciada por juez incompetente, legalmente implicado o cuya recusación se encuentre pendiente o hubiese sido declarada por tribunal competente;/ b) Hubieren sido violadas las disposiciones establecidas por la ley sobre publicidad y continuidad del juicio, o cualquier otro requisito para los cuales la ley haya previsto la nulidad o lo haya declarado expresamente como esencial;/c) La sentencia contuviere decisiones contradictorias, hubiere otorgado más allá de lo pedido por las partes, o se hubiere extendido a puntos no sometidos a la decisión del tribunal, sin perjuicio de las facultades para pronunciarse de oficio que la ley expresamente le otorgue, y/ d) La sentencia haya sido dictada contra otra pasada en autoridad de cosa juzgada y hubiere sido ello alegado oportunamente en el juicio;/ En esos casos, si la Corte acogiese el recurso, junto con anular la sentencia deberá determinar el estado en que bubiere de quedar el procedimiento, ordenando remitir los antecedentes al tribunal que corresponda. No producirán nulidad aquellos defectos que no influyen en lo dispositivo del fallo, sin perjuicio de las facultades de corregir de oficio que tiene la Corte durante el conocimiento del recurso". (Biblioteca Nacional del Congreso, Historia de la Ley $N^{\circ} 20.087$, pp. 190 y 191).

${ }^{9}$ Término empleado para referirse a las instancias de carácter casacional que se realizan por un órgano que no es el más Alto Tribunal. Hablamos de pequeña casación debido a que se requieren motivos tasados y no solo el agravio de la resolución que es lo lógico para la apelación.

${ }^{10}$ En este sentido, véase: Delgado CAStro, Jordi, El “certioriari": Un agente extraño en manos de nuestra Corte Suprema en Revista Actualidad Jurídica, 22 (Universidad del Desarrollo, 2010), pp. 361 ss.

${ }^{11}$ Biblioteca Nacional del Congreso, Historia de la Ley $N^{\circ} 20.087$, pp. 521 a 742. 
En los mismos términos se publicó la Ley $\mathrm{N}^{\circ} 20.087$. Se configuró un recurso de apelación laboral que mucho se parecía a un recurso de casación. Se coartaba la tradicional doble instancia, pero de bien seguro se obtenía un pronunciamiento rápido al evitar, sistemáticamente, el acceso a la Corte Suprema. Era una apuesta a favor de la rapidez a costa de los derechos del litigante.

A pesar de la publicación de la Ley $\mathrm{N}^{\circ} 20.087$, el legislador quiso seguir trabajando en propuestas destinadas a mejorar la justicia laboral y, especialmente, su procedimiento. El principal objetivo de esta reelaboración pasaba por mejorar el nuevo procedimiento monitorio. Aunque esta reforma trajo la incorporación del recurso de unificación de jurisprudencia.

La tramitación de la Ley $\mathrm{N}^{\circ} 20.260$ dejó al descubierto varios axiomas que habían alcanzado la categoría de auténticos mitos y que tuvieron intensa influencia en el sistema de recursos procesales ${ }^{12}$. De hecho, solamente las observaciones más enfáticas de la Corte Suprema hicieron entregar mayor protagonismo al alto tribunal ${ }^{13}$. Sin duda, aquellas indicaciones dieron sus frutos ya que antes de que entrase en su tramitación al Senado el proyecto de ley fue incorporando cada vez un papel más activo y central de la Corte Suprema.

Será el Senado quien nos entregue por primera vez en la historia un recurso exclusivamente destinado a la unificación de la jurisprudencia ${ }^{14}$.

Las distintas consideraciones que fueron surgiendo conforme al insólito régimen recursivo detonó, finalmente, un cambio sustancial configurado

\footnotetext{
${ }^{12}$ Así, por ejemplo, el señor Jaime Dinamarca Gárate, gerente de Operaciones y Medio de la Sociedad de Fomento Fabril, expresó su contrariedad a eliminar el recurso de apelación basado en una supuesta contraposición a la oralidad. Además, fue de los primeros en reclamar un papel activo en manos de la Corte Suprema como garante de la uniformidad de la jurisprudencia en contra a la extraña apelación que le confería la Ley $\mathrm{N}^{\circ} 20.087$ (Biblioteca Nacional del Congreso, Historia de la Ley $N^{\circ} 20.260$, p. 31). También, el ministro de la Corte Suprema don Patricio Valdés Aldunate señaló que esa mezcla entre recurso de nulidad, apelación y casación podría tornarse en contra del principio de celeridad en la respuesta judicial si es que, como preveía, los abogados quisieren revivir el recurso de queja convirtiéndolo, igualmente, en un tercer recurso (Biblioteca Nacional del Congreso, Historia de la Ley $N^{\circ} 20.260$, p. 36).

${ }^{13}$ La Corte Suprema, mediante un informe fechado el 18 de julio de 2007, reclamó la aclaración de la extraña apelación y, sugirió que se diesen luces al papel de la misma a la hora de atender impugnaciones (Biblioteca Nacional del Congreso, Historia de la Ley $N^{\circ} 20.260$, p. 112).

${ }^{14}$ La Comisión de Trabajo y Previsión Social del Senado, mediante Oficio $\mathrm{N}^{\circ} \mathrm{T} /$ $\mathrm{N}^{\circ} 1 / 2008$, interpeló a la Corte Suprema sobre diversas modificaciones que había realizado. Destaca la introducción en el artículo 483 la creación de un recurso excepcional contra la resolución que falla el recurso de nulidad: recurso de unificación de jurisprudencia (Biblioteca Nacional del Congreso, Historia de la Ley $N^{\circ} 20.260$, p. 209).
} 
por un recurso de nulidad muy parecido a una "pequeña casación" (tanto en el fondo como en la forma), aunque abandonando el nombre de apelación laboral, y un recurso de unificación de jurisprudencia que coordina las interpretaciones de los Tribunales Superiores de Justicia. Los siguientes momentos en el camino procedimental no introdujeron variaciones en lo esencial, de modo que quedará establecido este singular medio de impugnación desconocido en nuestro Derecho hasta el momento ${ }^{15}$.

\section{ORIGEN}

Como hemos podido observar el recurso de unificación de jurisprudencia nace en nuestra legislación en la tramitación de la Ley $\mathrm{N}^{\circ} 20.260$. Es un recurso ajeno, totalmente, a nuestra legislación anterior y prácticamente desconocido en nuestro entorno cultural ${ }^{16}$.

En Derecho comparado se observaron antecedentes en la casación francesa o en el recurso que se interpone ante la Corte Suprema de EE.UU. ${ }^{17}$. Por otra parte, podríamos encontrar semejanzas en la "tesis vinculante" mexicana o en la "sumula vinculante" brasileña. No obstante, el precedente más directo que podemos encontrar es el recurso de casación para unificación de doctrina en el proceso laboral español ${ }^{18}$.

El recurso de casación para unificación de doctrina en el proceso laboral español es una especie dentro del género de la casación que constituye una creación auténtica motivada por el diseño de la planta judicial -estructura orgánica de los tribunales- de aquel país ${ }^{19}$.

${ }^{15}$ De los posteriores trámites que pueden consultarse no podemos más que destacar que en ninguna instancia posterior se cuestionó este medio de impugnación y que, incluso la Corte Suprema comprendía que venía a completar la función de unificación de jurisprudencia que se había sustraído del recurso de nulidad del que conocerán las Cortes de Apelación (Biblioteca Nacional del Congreso, Historia de la Ley $N^{\circ} 20.260$, pp. 366 a 368).

${ }^{16}$ Pudiera encontrarse un predecesor en el artículo 373 letra b) del Código Procesal Penal en la forma señalada por Halpern Montecino, Cecily - Humeres Noguer, Héctor, La intervención de la Corte Suprema en la nueva justicia del trabajo: el recurso de unificación de jurisprudencia, en Revista Actualidad Jurídica, 21 (Universidad del Desarrollo, 2010), p. 348.

${ }^{17}$ En este sentido, véase Biblioteca Nacional del Congreso, Historia de la Ley $N^{\circ} 20.260$, págs. 366 a 372 .

${ }^{18}$ Así lo consideró, entre otros, Rodolfo Caballero Muñoz en el Oficio $\mathrm{N}^{\circ} 50 \mathrm{del}$ Colegio de Abogados recibido en la Corte Suprema el 11 de noviembre de 2008.

${ }^{19}$ Campos Alonso, Miguel Ángel, El recurso de casación para unificación de doctrina. Puntos críticos, en Actualidad Laboral, 16 (1992), p. 309; Jiménez ForTea, Francisco Javier, La naturaleza jurídica de la casación para la unificación de doctrina laboral, en Actualidad Laboral, 3 (1998), p. 849; MARTínez EMPERAdor, Rafael, 
En España la casación laboral existe desde la Ley de 22 de julio de 1912 en que se modificó la regulación de los Tribunales Industriales creándose un recurso de casación por infracción de ley y quebrantamiento de forma del que conocía la Sala Civil del Tribunal Supremo. Ahora bien, desde sus inicios se atendieron a las particularidades propias del proceso laboral y, en especial, del diseño de la organización jurisdiccional ${ }^{20}$.

La evolución del recurso español se vio muy influenciada por la reforma de la casación civil de $1984^{21}$, ya que la entrada en vigencia del texto refundido de la Ley de Procedimiento Laboral de 1980, si bien es posterior a la Constitución de 1978, no hizo sino reproducir exactamente la situación anterior a la misma ${ }^{22}$. De mayor significado resultó el Real Decreto Legislativo $\mathrm{N}^{\circ}$ 521/1990, de 27 de abril, que desarrolla, entre otras, la base $35^{\text {a }}$ de la Ley $\mathrm{N}^{\circ}$ $7 / 1989$, de 12 de abril, y por el cual se introdujo en el ordenamiento jurídico español el recurso de casación para unificación de doctrina ${ }^{23}$.

Por lo tanto, hace veinte años que nació este recurso. En todo este tiempo no se ha modificado ni una coma del texto normativo que lo contempla y, además, se ha conseguido que la Sala de lo Social del Tribunal Supremo sea la más efectiva en el sentido de la más eficaz, si consideramos que la eficacia es la entrega ágil de un pronunciamiento jurisdiccional firme.

Si bien es cierto que la respuesta es más rápida y que ha contribuido a mitigar hasta casi hacer desaparecer el clásico colapso que viven los órganos casacionales, no es menos cierto que los derechos del ciudadano que, sea directa o indirectamente, es quien financia la Justicia se han visto conculcados en atención a que las excesivas formalidades impuestas, no atienden a la obtención de una justicia más rápida, sino sólo una respuesta más rápida ${ }^{24}$.

Recursos de casación y suplicación en materia laboral: Puntos criticos (I), en Actualidad Laboral, 3, (1989), pp. 474-475; Molero Manglano, Carlos, La jurisdicción social en el proceso laboral, ahora, en SÁnchez-Cervera VAldés - López Álvarez - MAtorras Díaz-Caneja, Manual de Derecho del Trabajo,(Madrid, Mc.Graw-Hill, 2006), p. 527; Montoya Melgar, Alfredo, La concepción del recurso de casación para unificación de doctrina en la jurisprudencia del Tribunal Supremo, en Aranzadi Social, 13 (1998), p. 739.

${ }^{20}$ Mur BELLIDo, Francisco, El recurso de casación laboral (Según la legislación espanola y la doctrina de la Sala VI del Tribunal Supremo) (Madrid, Tecniban, 1969), p. 5.

${ }^{21}$ RuIz VAdillo, Enrique, La casación social. Consideraciones en torno a la reforma de la Ley de Enjuiciamiento Civil de 6 de agosto de 1984, en Relaciones Laborales, 2 (1987), p. 225

${ }^{22}$ Rodríguez-Piñero Royo, Miguel, El recurso de casación para unificación de doctrina: revisión critica (Madrid, La Ley, 1999), p. 21.

${ }^{23}$ Pérez Pérez, Manuel, Debate sobre el recurso de casación para la unificación de doctrina, en Temas Laborales, 34 (1995), p. 9.

${ }^{24}$ Para una correcta comprensión puede consultarse: Delgado CASTRo, Jordi, La historia de la casación civil española: una experiencia que aconseja no avanzar en el 


\section{PRimeras obSERVACIONES DERIVAdAS DE LAS CARACTERÍSTICAS DEL RECURSO}

El recurso de unificación de jurisprudencia se encuentra regulado, prioritariamente, en los artículos 483 a 484 del Código del Trabajo. Debido a su novedad y ausencia de referente tradicional con que compararlo, consideramos que va ser generador, durante largos años, de debate en la doctrina. Más, si cabe, debido a que la Reforma Procesal Civil crea un recurso que, guardando algún parecido con éste, va todavía más allá. Por lo que pueda ser entendido como antecedente natural, y por lo tanto referente obligado a cualquier análisis procesal del recurso extraordinario que se encuentra, todavía, en el Proyecto de Código Procesal Civil.

Por otra parte, muy apasionada se puede tornar esa discusión en la doctrina debido al valor que adquiere la jurisprudencia, casi fuente directa de Derecho, tanto en la disciplina laboral, como para el Derecho procesal. Nuestro enfoque va a ser estrictamente procesal al ser nuestra especialidad.

El recurso de unificación de jurisprudencia está dotado de las clásicas características de un recurso de corte casacional ${ }^{25}$. En este entendido, consideramos oportuno analizarlo bajo el prisma de las características que la doctrina ha destacado para el recurso de casación en el fondo ${ }^{26}$.

Resulta, entonces, que nos encontramos con un recurso que resulta más que extraordinario, puesto que es un recurso excepcional. Así la propia redacción del artículo 483 del Código del Trabajo lo indica. Siempre hemos sabido que el recurso de casación, fuere en la óptica que fuere, es un recurso extraordinario ${ }^{27}$ o también llamado de Derecho estricto ${ }^{28}$. La extraordinarie-

modelo de unificación de la doctrina, en Revista de Derecho de la Pontificia Universidad Católica de Valparaiso. 33 (2009), p. 359.

${ }^{25}$ Halim MuÑoz, Fernando Andrés, El recurso de unificación de jurisprudencia laboral, (Santiago, Thompson Reuters PuntoLex, 2010), pp. 47-48.

${ }^{26}$ Casarino Viterbo, Mario, Manual de Derecho Procesal (Derecho Procesal Civil) (Santiago, Editorial Jurídica de Chile, 2008), pp. 195-196, indica que las notas propias del recurso de casación en el fondo son: que se trata de un recurso extraordinario; que se interpone ante el órgano que dictó la resolución que se quiere impugnar; que se trata de un recurso de Derecho estricto; que beneficia a las partes y al interés público; que procede contra sentencias inapelables y, finalmente, que no constituye instancia.

${ }^{27}$ Oberg Yáñez, Héctor - Manso Villalón, Macarena, Recursos procesales civiles. Recursos de reposición, aclaración rectificación, queja, apelación, hecho y casación (Santiago, LexisNexis, 2006), p. 76; TAvolari Oliveros, Raúl, Recurso de casación y queja. Nuevo régimen (Santiago, ConoSur, 1996), p. 45; Troncoso Martinic, Pedro, Casación en el fondo civil y casación oficial (Santiago, Editorial Jurídica de Chile, 1992), p. 70.

${ }^{28} \mathrm{Si}$ bien estas dos características, en ocasiones, se han querido ver como sinónimos, consideramos que apuntan a realidades distintas. No es lo mismo observar ciertas for- 
dad indica que sólo se podrá interponer una vez agotadas las vías ordinarias de impugnación, limitándose el número de resoluciones que van a poder ser conocidas por la Corte Suprema. A su vez, el órgano jurisdiccional debe orientar su cometido a destacar los errores sin entrar a juzgar de nuevo el fondo del asunto ${ }^{29}$. Además, habitualmente se han establecido una serie de causales taxativas que permiten el acceso al recurso en determinados supuestos.

El legislador, conocedor de la dogmática propia de los recursos, quiso enfatizar en la particularidad de que a partir de ahora el acceso a la Corte Suprema es excepcional. Uno de los modos más efectivos para disminuir el colapso propio del órgano jurisdiccional supremo es la limitación extrema del número de asuntos que pueden llegar a su conocimiento. Por este motivo, la aplicación de este recurso debe ser restrictiva

De modo que el legislador creó el escenario para que la Corte Suprema inadmita de forma sistemática recursos y se convierta en un órgano meramente resolutor de contradiccione ${ }^{30}$, despojándolo de su función de proteger el ordenamiento jurídico.

El problema se verá cuando la Corte comience a entender al extremo dicha excepcionalidad, inadmitiendo sistemáticamente recursos en atención al incumplimiento de la identidad entre las materias y la disparidad entre las interpretaciones ${ }^{31}$.

Por otra parte, como segunda característica, el recurso de unificación de

malidades que impugnar en atención a algunas limitaciones derivadas de la naturaleza de la resolución o del asunto.

${ }^{29}$ Paillás Peña, Enrique, Derecho procesal penal, (Santiago, Editorial Jurídica de Chile, 1986), p. 70.

${ }^{30}$ Walter Díaz, Rodolfo - Lanata Fuenzalida, Gabriela, Régimen legal del nuevo proceso laboral chileno, (Santiago, LegalPublishing, 2009), p. 253: "ya que la circunstancia habilitante para acceder a esa sede superior es precisamente la existencia de pronunciamientos contradictorios en la jurisprudencia”.

${ }^{31}$ Por ejemplo, en la sentencia de 5 de enero de 2010 (causa rol $N^{\circ} 8.875-09$ ) la Corte Suprema declara inadmisible un recurso: "teniendo especialmente en cuenta para asi resolverlo, el carácter excepcional que reviste el mecanismo de impugnación que se intenta, particularidad reconocida expresamente por el articulo 483 del estatuto laboral'. En el caso que se trae a colación el recurrente no cumplió a cabalidad, según la Corte Suprema, la obligación de contenida en el artículo 483 del Código del Trabajo, de modo que debió, simplemente, motivar indicando que no se cumplía con uno de los requisitos esenciales. Si bien es cierto que, también lo hizo, no comprendemos la necesidad de indicar que el recurso es excepcional, ya que cualquier recurso que no cumpla con los requisitos de admisibilidad debe ser rechazado. De ahí que nos surge la preocupación por cómo la Corte entenderá la excepcionalidad y las consecuencias que de esa concepción se puedan derivar. En idénticas circunstancias( falta de cumplimiento de un requisito de interposición) la Corte declaró el "carácter especialísimo y excepcional que reviste el libelo que se intenta” (Sentencia de 19 de noviembre de 2008. Causa rol N 5.925-08). 
jurisprudencia se interpone ante la Corte de Apelaciones, en el plazo de 15 días. Nos parece un plazo bastante breve. En 15 días deberemos encontrar una sentencia que en un caso similar contenga un pronunciamiento distinto, cosa que no siempre resultará sencillo. Además, consideramos necesario que el legislador promueva la creación de un repertorio oficial de jurisprudencia que permita una consulta ágil y oportuna de la jurisprudencia de los Tribunales Superiores de Justicia. A día de hoy, muy difícil resultará adivinar roles y fechas para tratar de encontrar una resolución de contraste.

En tercer lugar, podemos entender que este recurso tiene la particularidad de defender los derechos de la parte (ius litigatoris) y, de este modo, aprovechando el impulso de la parte y resolviendo la cuestión que ésta plantea, también se protege, a futuro, una determinada interpretación. Se promueve, así, la defensa del ius constitutionis y, si consideramos que esa posición uniformada genera algún tipo de condicionante en los tribunales jerárquicamente dependientes de la Corte Suprema, incluso añade una protección mayor a la defensa de la ley en sí misma. Esta característica se cumple mediante el doble rol que perpetra el recurso persiguiendo la nulidad de la resolución impugnada, de una parte, y la enmienda y creación u opción de la doctrina jurisprudencial, por otra.

Como cuarta característica, debido a que el recurso de nulidad se configura como una especie de casación y al carácter excepcional, podemos llegar a considerar este recurso como una segunda casación frente a las resoluciones ya revisadas de forma extraordinaria en sede de Corte de Apelaciones.

Y, finalmente, considerando que no se revisan hechos sino sólo el Derecho, podemos también entender que no conforma instancia, pero sí un tercer grado jurisdiccional de revisión de la corrección de las decisiones, en atención al conocimiento derivado de la contradicción en la jurisprudencia.

\section{ASPECTOS PROBLEMÁTICOS A TRAVÉS DE LA TRAMITACIÓN}

Por tramitación debe entenderse la sucesión de secuencias procedimentales en que se va a desarrollar el conocimiento del recurso. Comprendería, por lo tanto, a los actos jurídico procesales que se desarrollan desde la interposición, hasta el fallo del recurso. En el caso del recurso de unificación de jurisprudencia encontramos las clásicas fases de los recursos devolutivos con momentos diferentes ante órganos distintos.

\section{Tribunal"a quo".}

El recurso se interpone ante la Corte de Apelaciones en el plazo de quince días desde la notificación de la sentencia que se recurre. Una correcta lectura de lo prescrito en el artículo 483-A nos indicará que las únicas resoluciones 
que se pueden impugnar son las sentencias definitivas, ya que solamente éstas fallan el recurso de nulidad.

El escrito de interposición debe contener una relación precisa y circunstanciada de las "distintas interpretaciones" respecto de las materias de Derecho que se pretendan impugnar. Hubiera sido deseable, que aprovechando que se creaba un mecanismo de impugnación novedoso, el control de admisibilidad en relación a cuestiones relativas al fondo del asunto lo hiciera directamente la Corte Suprema. El órgano a quo adolece de incompatibilidad psicológica y, además, ha perdido la debida imparcialidad objetiva ${ }^{32}$, pues ya conoció del fondo del asunto. Sin embargo, el propio Código del Trabajo solamente permite el rechazo del escrito si este se presenta fuera de plazo y, además, de forma muy garantista permite reponer la resolución que inadmita de plano. Ante la opción legislativa es totalmente destacable que sólo se comprueben cuestiones formales, y hasta podría haberse realizado un análisis muy somero sobre la auténtica existencia de discrepancias jurisprudenciales; en todo caso, hubiéremos preferido que este trámite lo realizara la propia Corte Suprema ${ }^{33}$.

El principal problema será conocer el alcance de la expresión precisa y circunstanciada. Por otra parte, pareciera que se está sentando, si quiera indirectamente, el motivo del recurso: la enmienda de las "distintas interpretaciones" respecto a las materias de Derecho objeto de la sentencia. De modo, que nuestra primera característica sobre el carácter casacional del recurso se ve seriamente comprometida. El motivo de todo recurso de casación es la corrección de la infracción de ley o de Derecho. Ante este panorama, entendemos y compartimos que el legislador optase por eliminar la denominación casación de este recurso.

La Corte Suprema ha adquirido un nuevo papel: Academia de sabios jurisconsultos que con vocación nomofiláctica sólo corrigen contradicciones. De este modo, se está excluyendo a la Corte Suprema y a las mejores cabezas de la judicatura de la posibilidad de juzgar y hacer ejecutar lo juzgado.

Cada avance que vamos realizando en nuestra descripción, nos va abriendo más interrogantes. Pensemos en que la Corte Suprema va a resolver discrepancias en materia de Derecho, ahora bien ¿no pueden ser dos decisiones

${ }^{32}$ Vallespín Pérez, David, Comentario a la STS(1a) de 22 de diciembre de 1999 en que se analiza la problemática de la imparcialidad objetiva en el proceso civil, en Revista Vasca de Derecho Procesal y Arbitraje, 1 (2001), pp. 11-18.

${ }^{33}$ Nieva Fenoll, Jordi, La casación en materia social ("ordinaria" y por unificación de doctrina): la decadencia de la casación, en Relaciones Laborales, 15-16 (2004), p. 578. 
contrarias correctas? $?^{34} y$, por otra parte, ¿la Corte Suprema ha de adoptar una de esas decisiones? O bien, ¿puede generar una doctrina distinta?

Vamos a necesitar del transcurso de varios años para que la Corte Suprema vaya contestando todas estas interrogantes mediante su jurisprudencia. Pero imaginamos, que dos decisiones contrarias pueden ser correctas y también creemos que la Corte no está obligada por las decisiones precedentes, ni tan siquiera por lo que ella misma sostuvo.

En este extremo el máximo problema va a resultar de averiguar qué son “distintas interpretaciones". Por una parte, podemos entender que "distintas interpretaciones" son distintas argumentaciones y, por otra, podemos pensar en distintos fallos. La Corte entiende que debe tratarse de fallos distintos emanados de hechos iguales. Es decir, el término de comparación ha de ser similar, ya que sino carece totalmente de sentido tratar de unificar doctrinas que ni se asemejan ${ }^{35}$.

No resulta baladí la distinción. Pensemos que con interpretaciones argumentales diferentes podemos llegar a fallos iguales de manera que la Corte Suprema se vería en la dificultad de discernir si existen o no "distintas interpretaciones". En todo caso, el recurrente estaría totalmente legitimado a interponer el recurso ya que pese a que el fallo le favoreciera totalmente, la argumentación podría generarle un gravamen que requiriera de reparación ${ }^{36}$. En ocasiones, puede producirse un perjuicio simplemente, por la desestimación de defensas o excepciones susceptibles de producir efectos reflejos derivados de los efectos colaterales que pudiera producir la cosa juzgada: no es lo mismo, por ejemplo, simplemente tener la razón en cuanto a la valoración de los hechos, que tenerla por la prescripción de la acción.

Pareciera, entonces, que el legislador estaba pensando más bien en fallos

${ }^{34}$ En opinión de Rodríguez Grez, Pablo, Teoria de la interpretación jurídica, (Santiago, Editorial Jurídica de Chile, (1995), p. 43: "las situaciones semejantes deben resolverse de la misma manera". Si bien esto es cierto, no lo es menos que "por otra parte corresponde señalar que también se permitan distintas interpretaciones sobre igual aspecto jurídico" (sentencia de 15 de junio de 2010. Causa rol $\mathrm{N}^{\circ} 1.312$ ).

${ }^{35}$ Causa rol N ${ }^{\circ} 7.335-08$ [Halpern Montecino, Cecily - Humeres Noguer, Héctor, cit. (n. 16), p. 351]. En similares términos, véase la más reciente sentencia de 7 de octubre de 2010, causa rol N ${ }^{\circ} 3.903-10$.

${ }^{36}$ Desde las Siete Partidas de Alfonso X, se ha considerado fundamento del recurso el gravamen causado. Así, en la Partida Tercera, Ley 2a, Título 23: "Alzarse puede todo ombre libre de iuycio que fuese dado contra el si se toviere por agraviado". Generalmente, se ha entendido ese gravamen como la diferencia entre lo pretendido por los litigantes y lo reconocido en la resolución. En este sentido, véase: OrTells Ramos, Manuel, Derecho jurisdiccional, en Montero Aroca - Gómez Colomer - Montón Redondo, Derecho jurisdiccional (Valencia, Tirant lo Blanch, 1997), p. 319; Prieto-Castro y Ferrándiz, Leonardo, Derecho procesal civil, (Madrid, Tecnos, 1974), p. 246. 
distintos. Debemos, en este punto, también reservar nuestro recelo en tanto no sepamos cómo va a interpretar y consolidar la Corte Suprema. Pudiera ser que el Alto Tribunal entienda que sólo va a entrar a corregir fallos opuestos, o quizá sólo fallos distintos. Ya que podemos volver a encontrarnos con que los fallos distintos en sí mismos no tienen porqué ser fuente de desigualdad, o mejor dicho gravamen para el recurrente. Aparentemente, los fallos opuestos sí generaran ese requisito inherente a todo recurso.

El artículo 483-A del Código del Trabajo parece arrojar alguna luz. El texto legal afirma que esas "distintas interpretaciones" deberán contenerse en "diversos fallos emanados de los Tribunales Superiores de Justicia". Así que, pareciera que el legislador sólo quiere unificar doctrinas reflejadas en el fallo de las resoluciones, evitando, por lo tanto, la corrección de las doctrinas argumentativas.

En este momento, comprobamos con agrado que como término de comparación de las resoluciones que se puedan invocar como "distintas interpretaciones" se encuentran recogidas las de la Corte Suprema ${ }^{37}$. Por lo tanto, y de forma acertada, se está resguardando la independencia de las Cortes de Apelación que podrán dictar resoluciones distintas a las que emanen de la Corte Suprema, aun a riesgo de ser unificadas.

Al escrito de interposición se deberá acompañar la copia de los fallos que se pretenda comparar. La Corte Suprema ha indicado que esas copias deben ser fidedignas ${ }^{38}$. De este modo, consideramos imprescindible la creación de una colección oficial de jurisprudencia ${ }^{39}$. Pudiera ser que algún recurrente poco avezado y dado lo breve del plazo, no pudiera recabar una copia fidedigna en el plazo, precluyendo su derecho a interponer el recurso y perdiéndose

${ }^{37}$ Así lo indicó la propia Corte Suprema en la causa rol N ${ }^{\circ}$ 5.164-08, en el modo indicado por Halpern Montecino, Cecily - Humeres Noguer, Héctor, cit. (n. 16), p. 349. Incluso la Corte Suprema ha admitido la posibilidad de fundamentar el recurso en interpretaciones divergentes anteriores a la reforma laboral.

${ }^{38}$ Sentencia de 19 de noviembre de 2008, causa rol N ${ }^{\circ}$ 5.952-08; Sentencia de 14 de julio de 2009, causa rol $\mathrm{N}^{\circ} 2.886-09$; Sentencia de 19 de agosto de 2010, causa rol $\mathrm{N}^{\circ} 2.821-10$.

${ }^{39}$ No parece razonable que algunos recursos no se hayan conocido por faltar un requisito que no impone la ley sino que surge de la creación jurisprudencial. En este sentido, la sentencia de 19 de noviembre de 2008 (causa rol $N^{\circ}$ 5.952-08) afirma: "el recurso no podrá prosperar, toda vez que si bien el recurrente ha pretendido dar cumplimiento a las cargas que le impone la ley para la procedencia de su arbitrio, dich a observancia no ha sido tal, por cuanto un examen somero de las sentencias en las que apoya la unificación de jurisprudencia que intenta, permite advertir que dichas copias además de no estar autorizadas están materialmente incompletas, circunstancia que lleva a este tribunal a estimar que, en su formalización, no se ha dado debido cumplimiento a los requisitos que la ley establece". 
el impulso privado como motor de la defensa del ordenamiento jurídico, por un formalismo fácilmente salvable ${ }^{40}$.

Otro de los requisitos de los que se ha hecho eco la Corte Suprema es que para poder comenzar a considerarse la necesidad de unificar, será necesario que existan a lo menos dos sentencias sobre la materia de Derecho que se quiere unificar ${ }^{41}$. Es decir, la Corte entiende que una sola sentencia no amerita la "unificación de jurisprudencia", de este modo, se deja ver que la finalidad del recurso puede llegar al absurdo de uniformar doctrinas erróneas, pero constantes. Una de las debilidades más importantes que detectamos en este recurso es, precisamente, que no busca corregir la decisión judicial directamente, sino que se enfatiza, en demasía, la entrega de una respuesta igual para todos.

Ahora bien, de la lectura de algún fallo del órgano jurisdiccional supremo en relación con la propia letra de la ley podemos destacar alguna discordancia. El artículo 483 afirma que las "distintas interpretaciones" deben ser contenidas en uno o más fallos. De este modo, la Corte Suprema al exigir más de un pronunciamiento está distinguiendo donde no lo hace la ley ${ }^{42}$. Es más, la propia Corte Suprema habla de "interpretaciones sostenidas en uno o más fallos firmes emanados de los tribunales superiores de justicia”" ${ }^{3}$. Sin embargo, la postura que ha adoptado la Corte Suprema es exigir dos o más fallos ${ }^{44}$. Poco podemos considerar unificar jurisprudencia cuando sólo existe un fallo

${ }^{40}$ Taruffo, Michele, El vértice ambiguo (Lima, Pelastra Ediciones, 2005).

${ }^{41}$ Así lo indicó la propia Corte Suprema en la causa rol N $\mathrm{N}^{\circ} 7.335-08$, tal y como señalan Halpern Montecino, Cecily - Humeres Noguer, Héctor, cit. (n. 16), p. 351 .

${ }^{42}$ Incluso la propia Corte Suprema pareciera, en ocasiones, no tenerlo tan claro cuando, por ejemplo, hace afirmaciones como que se debe "acompañar la copia fidedigna del o de los fallos que se invocan como fundamento" (Sentencia dictada el $31 \mathrm{de}$ marzo de 2010, causa rol $\left.N^{\circ} 8.809-09\right)$ no quedando claro si se puede tratar de uno, u obligatoriamente ha de ser más de uno.

${ }^{43}$ Sentencia dictada el 19 de agosto de 2010, causa rol N².821-10. Quizá, con el objeto de no reconocer que pueda ser un solo fallo, la Corte Suprema ha ido empleando otras fórmulas al referirse a los requisitos como, por ejemplo, en sentencia de 15 de junio de 2010 (causa rol No 3.357-10): "sostenidas en diversos fallos emanados de tribunales superiores de justicia".

${ }^{44}$ En sentencia dictada el 21 de abril de 2010 (causa rol N 9.024-09) la Corte, en forma diáfana, deja sentado que: "Que dada la conceptualización que el legislador ha hecho del recurso de que se trata, como lo ha dicho ya esta Corte, se constituye como un factor sine qua non para concluir una alteración en la orientación jurisprudencial de los tribunales superiores de justicia respecto de alguna determinada materia de Derecho objeto del juicio, la concurrencia de al menos dos resoluciones, que sustenten igual línea de razonamiento al resolver litigios de idéntica naturaleza". En idéntico sentido, véase sentencia dictada el 31 de marzo de 2010, causa rol Nº 8.809-09. 
discordante con el nuestro. Sin embargo, la Ley pareciera abrir la posibilidad a esa posibilidad, a que ningún fallo quede en contradicción con otro. Por otra parte, debemos destacar el acierto que tanto la ley como la Corte han señalado que los fallos que se impugnen sean firmes. Por el mismo motivo, sería absurdo unificar fallos que estén pendientes de recurso y, eventualmente, puedan cambiar su signo.

Finalmente, a este respecto, debemos señalar que las sentencias ${ }^{45}$ que se pueden presentar como término de comparación son aquellas dictadas por las Cortes de Apelaciones y la Corte Suprema ${ }^{46}$. Excluyéndose, de este modo, las sentencias dictadas por los Jueces de Letras ${ }^{47}$.

Motivada por el objetivo de expandir al máximo la uniformidad de la jurisprudencia la Corte Suprema ha matizado que se pueden comparar como referenciales otras resoluciones además de las sentencias que resuelven recursos de nulidad ${ }^{48}$.

${ }^{45}$ No admitiéndose otro tipo de resoluciones, como por ejemplo, escritos que resuelven inadmisiones. En este sentido, la sentencia de 19 de agosto de 2010. Causa rol $\mathrm{N}^{\circ} 2.821-10$, exponía que no podía considerar una de las resoluciones como término de comparación puesto que: "el recurso de casación en el fondo fue desestimado en el trámite de la admisibilidad”. Entendiéndose, de esta manera, que sólo las sentencias definitivas que resuelven poniendo fin a la instancia son aptas para ser unificadas.

${ }^{46} \mathrm{La}$ Corte Suprema precisó que por Tribunales Superiores de Justicia debe considerarse solamente a las Cortes de Apelación y Corte Suprema. Así lo declaró expresamente en la causa rol № 5.164-08: "Que para los efectos de entender cumplido el requisito relativo a acompañar copias del o de los fallos que se invocan por el recurrente como fundamentos de su recurso, es dable señalar, como ya se dijo, que ellos deben emanar de los tribunales superiores de justicia, entendiéndose por tales las Cortes de Apelaciones y la Corte Suprema, según se desprende del sistema jerarquizado conforme al cual se encuentran organizados los tribunales ordinarios. Asi, dentro de dicho sistema, se distingue entre superiores e inferiores, clasificación recogida, en principio en los artículos $52 N^{\circ}$ 2, letra c) y 53 $N^{\circ} 3$ de la Constitución Politica de la República, a propósito de las atribuciones exclusivas de la Cámara de Diputados y del Senado. Tal distinción encuentra amparo, además, en la regla de la doble instancia que rige en nuestra legislación, especialmente consagrada en el artículo 110 del Código Orgánico de Tribunales y en la competencia que, según la naturaleza del asunto debatido o el fuero de los intervinientes, asigna la ley. En consecuencia, la acompañada sentencia de primera instancia dictada por el Primer Juzgado del Trabajo de Magallanes no satisface la exigencia contemplada en el citado artículo 483 A del Código del ramo." De modo, que parece excluirse a las antiguas Cortes de Trabajo.

${ }^{47}$ Sentencia de 5 de noviembre de 2009, causa rol N ${ }^{\circ} 7.216-09$.

${ }^{48}$ Entre otras, en la sentencia de 7 de octubre de 2010 (causa rol No 3.903-10) la Corte Suprema admite como resoluciones referenciales una sentencia dictada en resolución de un recurso de casación en el fondo y otra que resolvía una casación en el fondo de oficio. Por lo tanto, la labor de la Corte Suprema será más permisiva de lo que cabía esperar en una lectura restrictiva de los preceptos del Código del Trabajo. De este modo, además, se otorga vigencia a la jurisprudencia anterior a la reforma tal y como 
Una vez interpuesto el recurso debemos saber que no se suspende la ejecución de la resolución impugnada a no ser que su cumplimiento imposibilite la realización de la eventual sentencia dictada acogiendo el mismo. El recurrente deberá solicitar, si lo considera oportuno, que el recurrido preste fianza de resultas para responder en caso de que se acoja el recurso. Esta petición deberá realizarse en conjunto con el escrito de interposición, pero en forma separada.

Por su parte, la Corte de Apelaciones elevará a la Corte Suprema los antecedentes necesarios para su conocimiento remitiendo, especialmente, la copia de la resolución que resuelve el recurso de nulidad y que se está impugnando.

\section{Tribunal "ad quem".}

Una vez se encuentra el expediente en el Tribunal ad quem volvemos a encontrar problemas. La Corte Suprema puede inadmitir en dos supuestos. En primer lugar, podrá inadmitir el recurso por haberse presentado extemporáneamente, es decir, más allá de los quince días que prescribe la ley. Pues bien, consideramos poco oportuno que una operación tan sencilla se deje en manos de la Corte Suprema, cuando, además, se presupone que la Corte de Apelaciones ya ha comprobado este requisito. Si bien es cierto que resulta una operación intelectual rápida, observamos que no es acertado como política un doble control sobre la oportunidad de la interposición. Esta crítica sería fácilmente solucionable permitiendo un único control de admisibilidad por parte de la propia Corte Suprema.

La segunda causal por la que la sala especializada puede inadmitir nos parece mucho más acertada: el análisis del fundamento del escrito, de la relación precisa y circunstanciada de las "distintas interpretaciones" en materia de Derecho sostenidas en diversos fallos. En esta fase y dependiendo de la predisposición que adopte la Corte Suprema pueden llegar a perecer la mayoría de los recursos. Pese a ser un análisis formal de los requisitos, va a ser muy sencillo que el Tribunal crea que no existe una relación precisa y circunstanciada, o que no hay "distintas interpretaciones"

indicó el Colegio de Abogados en el Oficio $\mathrm{N}^{\circ} 50$ recibido en la Corte Suprema el 11 de noviembre de 2008. Ahora bien, la Corte Suprema ha precisado que se debe tratar de sentencias que resuelvan sobre el fondo, y no otras resoluciones que, por ejemplo tienen por objeto inadmitir el conocimiento de un recurso. Así la sentencia de 28 de octubre de 2008 (causa rol N ${ }^{\circ}$ 5.164-08) establece que "no puede obtenerse como lo pretende el recurrente respecto de aquellos casos en que no se ha entrado al conocimiento de las argumentaciones sustantivas contenidas en un recurso, por haberse rechazado por manifiesta falta de fundamentos".

${ }^{49}$ Además, la Corte indicó expresamente en la causa rol N5.164-08 (señalado por 
En el fondo, se está obligando al recurrente a entregar absolutamente todos sus argumentos ya que si quisiera reservar alguno para un eventual alegato, podría encontrarse con la sorpresa de que su escrito ha sido inadmitido, debido al gran grado de interrelación entre este análisis de forma y el fondo del asunto. Hasta pudiera considerarse desigualdad en las armas procesales, ya que se obliga a que el recurrente avance en su escrito todos sus argumentos, mientras que la contraparte permanece inactiva durante todas estas instancias.

Afortunadamente, este trámite es recurrible en reposición. A pesar de lo inconveniente, se concede una posibilidad de defensa al recurrente, que querrá tratar de defender su derecho a alcanzar un pronunciamiento sobre el fondo.

En el caso de que el recurso se declare admisible, se concede la posibilidad de que el beneficiado por la resolución recurrida se haga parte en el plazo de diez días. Hasta este momento, no había habido momento procesal oportuno para que el vencedor del recurso de nulidad se manifestara. En resguardo de la igualdad de oportunidades se concede este mecanismo de audiencia al recurrido.

El recurso se conocerá previa vista de la causa y se observarán las normas que rigen en las apelaciones, limitándose los alegatos de cada parte a treinta minutos.

Una vez conocido el asunto, la Corte Suprema emitirá su fallo. El Código del Trabajo reconoce el efecto relativo de la sentencia, reconocido en el artículo 3 del Código Civil. Si bien es un principio básico comúnmente aceptado, surge, empero, la constatación de un hecho, a lo menos, grave. Es normal respetar la "santidad" de la cosa juzgada, ahora bien, el legislador ha abierto el camino para que sentencias juzgadas, firmes e inamovibles puedan ser cuestionadas con fundamento por quienes las sufrieron.

Es decir, el perjudicado por una sentencia que, ahora, observa cómo la Corte Suprema interpreta una materia en el sentido que en su día él sostuvo va a sufrir, a todas luces, una injusticia notoria, además de la correspondiente frustración y desencanto por el sistema de justicia. Es el gran inconveniente de este tipo de sistema, del uso de los precedentes ${ }^{50}$. Por nuestra forma de

Halpern Montecino, Cecily - Humeres Noguer, Héctor, cit. (n. 16), p. 351) que las resoluciones dictadas en cuenta de admisibilidad no producen efecto vinculante. De modo, que nunca se admitirán como término de comparación y, por lo tanto, nunca podrán ser enmendadas por la propia Corte Suprema en sede de uniformar criterios.

${ }^{50}$ En los últimos años ha habido una tendencia a acercarse al precedente tanto en Europa como en nuestro propio sistema. En este sentido, véase Romero SEGUEL, Alejandro, cit. (n. 3), pp. 14 ss. 
entender el Derecho, no podemos afectar a situaciones anteriores que gozan de autoridad de cosa juzgada, por una parte, y nunca sería de recibo modificar una sentencia en que no han intervenido las auténticas partes. Sin embargo, la parte que en su día tuvo que soportar un fallo en su contra, no va a entender cómo la Corte Suprema y, precisamente, tomando su caso como referente, entiende el Derecho en otro sentido ${ }^{51}$. Por este motivo, no compartimos la adopción de una línea jurisprudencial por parte de los Tribunales Inferiores que no desatienda una interpretación frente a casos similares a no ser que concurra una justificación suficiente y razonable ${ }^{52}$.

Es un acercamiento al modelo del precedente. La Corte Suprema va a unificar criterios a futuro ${ }^{53}$. Si, posteriormente, se crea una jurisprudencia uniforme, el recurrente siempre tendrá base para recurrir aquellas decisiones que se aparten de la jurisprudencia uniforme.

La sentencia que resuelve el recurso de unificación de jurisprudencia no se dicta como mera opinión de Derecho, sino que se dicta atendiendo a un supuesto determinado y haciendo derivar las consecuencias previstas por la ley. Es decir, no se trata de una sentencia con mera eficacia sobre la imposición de una determinada aplicación e interpretación de la norma, sino que también resuelve un debate judicial concreto.

En el supuesto de que la Corte Suprema considere que debe acoger el recurso deberá dictar, sin necesidad de otra vista, sentencia de remplazo en el que fije la unificación de la jurisprudencia ${ }^{54}$.

Ahora bien, el que el recurso sea conocido por la Corte y sea admitido a trámite no implica que vaya a ser acogido ${ }^{55}$. De hecho, es una práctica conocida el que los Tribunales Superiores admiten indistintamente recursos que caen en desestimación por la cuenta que da el Relator señalando los defectos que haya podido advertir.

${ }^{51}$ Esta misma preocupación se la comunicó el Colegio de Abogados (Oficio $\mathrm{N}^{\circ} 50$ recibido en la Corte Suprema el 11 de noviembre de 2008) a la Corte Suprema, indicando la eventual transgresión del artículo $19 \mathrm{~N}^{\circ} 3$ de la Constitución Política.

${ }^{52}$ En este sentido, véase Halpern Montecino, Cecily - Humeres Noguer, Héctor, cit. (n. 16), p. 365.

${ }^{53}$ Una vez la Corte Suprema adopta un criterio es posible que en el futuro reitere su interpretación. Puede consultarse el séptimo considerando de la sentencia dictada el 31 de marzo de 2010, causa rol N ${ }^{\circ} 8809-09$.

${ }^{54}$ En primer lugar la Corte Suprema deberá considerar "asentada la procedencia de la unificación de jurisprudencia requerida" para proceder a "acoger el recurso" (Sentencia de 15 de junio de 2010, causa rol $\mathrm{N}^{\circ} 1.984-10$; Sentencia de 15 de junio de 2010, causa rol $\mathrm{N}^{\circ}$ 2.975-10; Sentencia de 7 de octubre de 2010, causa rol $\mathrm{N}^{\circ} 3.903-10$ ).

${ }^{55}$ En el caso de que no se encuentre contradicción entre las resoluciones presentadas y, se den diferencias en la apreciación de los hechos, la Corte Suprema rechazará los recursos. Así por ejemplo, en sentencia de 15 de junio de 2010, causa rol N 1.670-10. 
Pensemos en el futuro (en clave de conclusión)

El recurso de unificación de jurisprudencia es un novedoso medio de impugnación que persigue dos objetivos imprescindibles como valor jurídico: la celeridad procesal, de una parte, y la igualdad en los pronunciamientos judiciales.

Ahora bien, las particularidades de nuestro sistema y de nuestra Corte Suprema han demostrado que el tradicional recurso de casación, que no es adalid de la máxima perfección, no es tan prescindible como el legislador quiere.

Terminar con un mal endémico de la Corte Suprema, como su tradicional colapso, no debe pasar por la implementación extrema de un recurso de unificación de doctrina, ni por traslaciones de modelos más propios de Estados Federales o de Derecho de corte anglosajón.

El recurso de unificación de jurisprudencia incorpora la respuesta rápida en su propia esencia. Es ágil en los tiempos de obtención de una respuesta del órgano jurisdiccional. Sin embargo, se limita el derecho de los litigantes tal y como lo conocemos, incorporando el requisito de la contradicción en sentencias dictadas por los tribunales superiores de justicia.

Los datos que podemos consultar ${ }^{56}$ nos indican que la gran mayoría de recursos son inadmitidos, desiertos o ni tan siquiera llegan a ser presentados. Por lo tanto, el efecto de la uniformidad de criterios mediante la actuación de la Corte Suprema queda en entredicho si es que se rechazan los asuntos por criterios formales.

Pero lo más preocupante que puede acarrear esta experiencia es que el legislador, animado por los excelentes resultados de eficacia-entendida como rapidez- difícilmente va abandonar la senda en sucesivas reformas.

En lo inmediato, la Reforma Procesal Civil incorpora un recurso con una lógica muy similar. El llamado recurso extraordinario se concibe como el medio idóneo para corregir el sistema, mediante la unificación de jurisprudencia con motivo de sentencias notoriamente injustas.

Seguramente, la casación tradicional tiene muchos inconvenientes y tiene las horas contadas, pero es un medio de defensa del interés del litigante y fomenta, además, la defensa del ordenamiento jurídico. Debería ser un desafío para el legislador del siglo XXI modernizar una figura decimonónica que aúna ambos objetivos claves en un sistema de justicia.

\footnotetext{
${ }^{56}$ En su preocupación por el estudio de la implementación de la Reforma Laboral, la Corte Suprema, mediante su Dirección de Estudio, Análisis y Evaluación, elaboró un informe ( $\mathrm{N}^{\circ}$ 26-2010) en que se presentan toda una serie de críticas acerca de la implementación del recurso de unificación de jurisprudencia. En ese estudio se indica que sólo un $12 \%$ de los recursos son acogidos, un $7 \%$ es rechazado y el $81 \%$ es declarado inadmisible, desierto o, simplemente, no se presentan.
} 
Esperemos que el 2011 y el Consejo Asesor para la Reforma Civil puedan orientar parte de sus esfuerzos a mejorar el sistema de recursos fortaleciendo la doble instancia y privilegiando el rol de la Corte Suprema como máximo intérprete de nuestro ordenamiento jurídico.

\section{BIBLIOGRAFÍA}

Alcalá-Zamora y Castillo, Niceto, Notas para la reforma de la Ley de Enjuiciamiento civil (Madrid, Estudios de Derecho Procesal, 1934).

Aragoneses alonso, Pedro, Notas sobre la casación y la jurisprudencia, en Revista de Derecho Procesal, 1 (2005).

Bonet Navarro, José, El recurso de casación civil (Cizur Menor, Aranzadi, 2010).

Campos Alonso, Miguel Ángel, El recurso de casación para unificación de doctrina. Puntos criticos, en Actualidad Laboral, 16 (1992).

Casarino Viterbo, Mario, Manual de derecho procesal (Derecho procesal civil) (Santiago, Editorial Jurídica de Chile, 2008).

Correa Selamé, Jorge, Recursos procesales civiles (Santiago, LexisNexis, 2007).

Delgado CASTRO, Jordi, El “certioriari": Un agente extraño en manos de nuestra Corte Suprema, en Revista Actualidad Jurídica, 22 (Universidad del Desarrollo, 2010).

Delgado CAstro, Jordi, La historia de la casación civil española: una experiencia que aconseja no avanzar en el modelo de unificación de la doctrina, en Revista de Derecho de la Pontificia Universidad Católica de Valparaiso, 23 (2009).

Halim MuÑoz, Fernando Andrés, El recurso de unificación de jurisprudencia laboral (Santiago, Thompson Reuters PuntoLex, 2010).

Halpern Montecino, Cecily - Humeres Noguer, Héctor, La intervención de la Corte Suprema en la nueva justicia del trabajo: el recurso de unificación de jurisprudencia, en Revista Actualidad Jurídica, 21 (Universidad del Desarrollo, 2010).

JimÉnEz ForTEA, Francisco Javier, La naturaleza jurídica de la casación para la unifcación de doctrina laboral, en Actualidad Laboral, 3 (1998).

MARTÍNEZ EMPERADOR, Rafael, Recursos de casación y suplicación en materia laboral: Puntos criticos (I), en Actualidad Laboral, 3 (1989).

Molero Manglano, Carlos, La jurisdicción social en el proceso laboral, ahora en Sánchez-Cervera Valdés - López Álvarez - Matorras Díaz-Caneja, Manual de Derecho del Trabajo (Madrid, McGraw-Hill, 2006).

Montoy Melgar, Alfredo, La concepción del recurso de casación para unificación de doctrina en la jurisprudencia del Tribunal Supremo, en Aranzadi Social, 13 (1998).

Mur Bellido, Francisco, El recurso de casación laboral (Según la legislación española y la doctrina de la Sala VI del Tribunal Supremo), (Madrid, Tecniban, 1969).

Nieva Fenoll, Jordi, La casación en materia social ("ordinaria" y por unificación de doctrina): la decadencia de la casación, en Relaciones Laborales, 15-16 (2004).

Oberg Yáñez, Héctor - Manso Villalón, Macarena, Recursos procesales civiles. Recursos de reposición, aclaración rectificación, queja, apelación, hecho y casación (Santiago, LexisNexis, 2006).

Ortells Ramos, Manuel, Derecho jurisdiccional, en Montero Aroca - Gómez Colomer - Montón Redondo (Valencia, Tirant lo Blanch, 1997).

Paillás Peña, Enrique, Derecho procesal penal, (Santiago, Editorial Jurídica de Chile, 1986). 
PÉREZ PÉREz, Manuel, Debate sobre el recurso de casación para la unificación de doctrina, en Temas Laborales, 34 (1995).

Prieto-Castro y Ferrándiz, Leonardo, Derecho procesal civil (Madrid, Tecnos, 1974).

Rodríguez Grez, Pablo, Teoría de la interpretación jurídica (Santiago, Editorial Jurídica de Chile, (1995).

Rodríguez-PiÑERo Royo, Miguel, El recurso de casación para unificación de doctrina: revisión critica (Madrid, La Ley, 1999).

Romero Seguel, Alejandro, La jurisprudencia de los tribunales como Fuente del Derecho (Santiago, Editorial Jurídica de Chile, 2004).

Ruiz VAdillo, Enrique, La casación social. Consideraciones en torno a la reforma de la Ley de Enjuiciamiento Civil de 6 de agosto de 1984, en Relaciones Laborales, 2 (1987).

Serra Domínguez, Manuel, El recurso de casación en la LEC 1/2000, en Revista Jurídica de Catalunya, 4 (2001).

TARuffo, Michele, El vértice ambiguo (Lima, Pelastra Ediciones, 2005).

Tavolari Oliveros, Raúl, Recurso de casación y queja. Nuevo régimen (Santiago, ConoSur, 1996).

Troncoso Martinic, Pedro, Casación en el fondo civil y casación oficial (Santiago, Editorial Jurídica de Chile, 1992).

VAllespín PÉRez, David, Comentario a la STS(1 $\left.{ }^{a}\right)$ de 22 de diciembre de 1999 en que se analiza la problemática de la imparcialidad objetiva en el proceso civil, en Revista Vasca de Derecho Procesal y Arbitraje, 1 (2001).

Walter Díaz, Rodolfo - Lanata Fuenzalida, Gabriela, Régimen legal del nuevo proceso laboral Chileno (Santiago, LegalPublishing, 2009). 